\title{
Reliability of face recognition performance
}

\author{
JUNE E. CHANCE and ALVIN G. GOLDSTEIN \\ University of Missouri, Columbia, Missouri 65211
}

\begin{abstract}
A group of 112 college students studied different sets of 16 faces on three occasions 1 week apart. They were asked immediately after each study trial to pick those 16 faces from among 48 distractor faces. Performances were scored for hits, false alarm rates, and $\mathrm{d}^{\prime}$ and $\beta$. A moderate degree of consistency was shown in the intercorrelations among performance measures for each of the 3 days, although the values were limited by the distribution of performances among subjects. Analysis of individual subjects' consistency over 3 days of the faces task shows that more than $50 \%$ of subjects perform consistently either above or below the means for performance of the total group.
\end{abstract}

Research studies of recognition memory for human faces have become increasingly numerous in recent years. In part this emergence of interest in faces represents an aspect of an increased interest in a study of memory that is integrated with the broader context of cognitive psychology (Clifford \& Bull, 1978; Neisser, 1967); however, the study of memory for faces also represents increased awareness on the part of psychologists of the important social contribution we are capable of making to improve criminal justice in this country (Buckhout, 1974; Goldstein, 1976). Particularly in this latter regard, the question of the reliability of face recognition performance becomes critical. Do observers show consistency in recognizing faces to an extent that makes assessing their consistency possibly useful in predicting eyewitness performance? Folklore among policemen, judges, and psychologists about characteristics-age, sex, intelligence, personality dispositions, and so on-associated with differential accuracy in making eyewitness identifications attests to the possibility that a "morning-after-the-crime face recognition test" might be a useful device for determining the degree of credibility of a given eyewitness.

A first question that must be answered before proposing to develop a predictor of general face recognition capability, that is, before expecting to find stable relationships between individual difference variables and face recognition performance, is the question of how reliable is face recognition performance generally? Do individuals show consistency across fairly large numbers of faces and from one occasion to another? The present study was undertaken to address this question.

An attempt to study the reliability of face recogni-

This research was funded by a grant from the Research Council of the Graduate School, University of Missouri, Columbia. The authors gratefully acknowledge the assistance of the following students in gathering and analyzing these data: Jerry Conover, David Funk, Mark Haldeman, Kenneth Skouby, and Stephanie Spalding. Data presented in this paper were originally presented as a part of a symposium titled "Memory for faces: Pattern recognition and eyewitness identification" at the 1978 meetings of the American Psychological Association at Toronto, Canada. tion in a laboratory with the aim of generalizing to reallife practices is a formidable venture. First, we, and our readers, should be aware that actual eyewitness performance is influenced by many situational variables that may outweigh the influence of any stable characteristics of the observer. Nonetheless, if we can assume that most of these situational influences on observers tend to be deleterious for performance (fear, startle, excitement, poor view, dim light, many competing events), we can propose that laboratory tests of face recognition under excellent conditions favoring accuracy ought to provide indications of the upper limits of observers' consistency of performance.

\section{METHOD}

A group of 112 (46 men and 66 women) undergraduate students volunteered to serve in a study in which they were tested for immediate face recognition memory on three occasions, separated by no less than 6 days. Testing was done in small groups of subjects. Only the data of Caucasian students were included in this analysis. Dropout attrition over the three sessions of the study was less than $5 \%$ of potential subjects.

Recognition stimuli were $2 \times 2$ in. colored slide portraits of 96 college women and 96 college men, all Caucasians. Each person had been photographed twice: once facing approximately $5 \mathrm{deg}$ to the right of the camera lens and once facing $5 \mathrm{deg}$ left. All models wore a blue cloth cloak to hide their clothing. Pictures were not taken, or portraits were not used, if the subject wore glasses or earrings or had noticeable facial scars or a marked facial expression. The resulting set of pictures are quite homogeneous in appearance.

Because we have found repeatedly in earlier face recognition studies that the particular pictures used for recognition is a highly important factor in subject performance (Chance, Goldstein, \& McBride, 1975), we routinely change the target sets and associated distractors within an experiment in order to reduce the possibility that study outcome is confounded with a particular sample of target faces. In this study, therefore, 144 of the 192 faces acted as target stimuli for some subjects and also served as distractors for other groups of subjects. All 192 faces at one time or another served as distractors. An attempt was made to equalize the number of subjects viewing each of the various target sets. These procedures should provide results that are reasonably free of effects of picture differences and therefore should be generalizable to other college-aged subjects recognizing peer faces. 
Subjects were told that their task was to attend to the pictures and that they would later be asked to pick out those seen before from among a new set of similar pictures. Instructions were the same at all three sessions. On the recognition trials, subjects indicated "old" or "new" picture by blocking Position 1 or 5 on a standard classroom optical scan answer sheet. Although subjects were told how many pictures they would see in each study series and how many total pictures were in each recognition test, no mention was made of whether to guess, and the machine answer sheet probably made it difficult to keep track of exactly how many "old" responses were being given.

In the study trials, 16 target faces were presented for $5 \mathrm{sec}$ each with about $.75 \mathrm{sec}$ between stimuli. The test trial, which followed immediately, was composed of the alternate pose of each of the 16 target people, plus 48 distractor faces. The target portraits were randomly intermingled among the distractors, and the sequence of their appearance was not systematically related to the study trial sequence. Each portrait was displayed for $5 \mathrm{sec}$ while subjects marked their response sheets.

On each of the 3 days of the study, subjects were asked to perform other visual recognition tasks and other memory tasks in addition to face recognition, but the faces task was the only task given repeatedly. It was always the task given first. Findings regarding the other tasks will be mentioned later but reported more fully elsewhere.

\section{RESULTS AND DISCUSSION}

The overall outcome of the study indicates that there is a moderate degree of intraindividual consistency in face recognition and perhaps even more consistency in false positive responding. Some sex differences and consistent group changes in performance were also found over the 3 days of the study.

Means of performance of face recognition on the 3 days of the study are shown in Table 1. Outcomes on four performance measures are presented: percentage of hits, percentage of false alarms, $\mathrm{d}^{\prime}$, and $\beta$. (Percentages of hits and false alarms were used since a few subjects claimed to have had previous exposure to at least one face shown during the study trials. Rather than eliminate these, we scored performances as percentages of previously unknown faces. However, only a tiny fraction of subjects have performances based on less than 16 pictures.)

Analyses of variance of the four performance measures over the 3 days of the study indicates that differences in mean performance occurred related to day of performance and to sex of subject. Percentage of hits and false alarms both decreased over the successive days of the study $[F(2,220)=20.42$ and 34.00 , respectively, $p<.0001]$, but no significant change occurred in $\mathrm{d}^{\prime}$. Results for $\beta$ show significant increase with successive exposures to the task $[F(2,220)=$ $31.15, \mathrm{p}<.0001]$. In other words, subjects asked repeatedly to recognize pictures of faces become less accurate in terms of hits, but in a compensating way become more cautious about making errors of commission.

Women on all 3 days of the study have significantly higher hit rates than do men $[F(1,110)=4.58, p<.03]$. They also tend to make fewer false alarm responses than do men $[F(1,110)=3.53, p<.06]$. In consequence, they also exceed men in the $\mathrm{d}^{\prime}$ measure $[F(1,110)=10.15, p<.002]$. Although women have a corresponding tendency to have higher mean $\beta$ scores than men on Days 2 and 3 of the study, these differences were not significant. The superiority of women's performance on face recognition confirms the work of many previous investigators, including work in our own laboratory (see Clifford \& Bull, 1978; Ellis, 1975, for reviews of sex differences in face recognition).

Table 2 presents the values of Pearson productmoment correlations among face recognition performances assessed by the four dependent measures on the successive days of the study. These values show a moderate degree of consistency among face recognition performances. However, the sizes of correlations obtained in this college population are quite likely to represent rather modest estimates of the degree of consistency that might be found in persons more diverse in ability and motivation. The descriptive data in Table 1 indicate that average number of hits on each trial with faces was $75 \%$ or more. Inspection of the raw data also revealed that on the first recognition trial for faces, $33 \%$ of the subjects obtained scores of more than $90 \%$ correct. The high frequency of such good performance tends to restrict the size of the correlations that can be obtained.

The correlations among rates of hits and $\mathrm{d}^{\prime}$ presented in Table 2 indicate that a moderate degree of intrasubject consistency in face recognition performance occurs when subjects view and recognize faces in a laboratory task on three occasions within 3 weeks. Nonetheless, the degree of consistency shown is not sufficient to encourage hope that individual performance can be predicted from a single sample of face recognition

Table 1

Face Recognition Performance (Mean Hits, False Alarms, $d^{\prime}$, and $\beta$ ) for 3 Days of the Study

\begin{tabular}{|c|c|c|c|c|c|c|c|c|c|c|c|c|}
\hline & \multicolumn{3}{|c|}{ Day 1} & \multicolumn{3}{|c|}{ Day 2} & \multicolumn{3}{|c|}{ Day 3} & \multicolumn{3}{|c|}{ Total } \\
\hline & $\mathbf{A}$ & W & $\mathbf{M}$ & A & W & $\mathbf{M}$ & $\mathbf{A}$ & W & $\mathbf{M}$ & A & W & $\mathbf{M}$ \\
\hline Hits & 84.00 & 87.00 & 80.00 & 77.00 & 79.00 & 75.00 & 75.00 & 76.00 & 74.00 & 78.66 & 80.67 & 76.33 \\
\hline False Alarms & 11.00 & 11.00 & 12.00 & 8.00 & 6.00 & 10.00 & 6.00 & 5.00 & 7.00 & 8.83 & 7.33 & 9.67 \\
\hline$d^{\prime}$ & 2.50 & 2.68 & 2.25 & 2.41 & 2.57 & 2.17 & 2.49 & 2.59 & 2.36 & 2.47 & 2.61 & 2.26 \\
\hline$\beta$ & 1.86 & 1.63 & 2.18 & 3.64 & 3.86 & 3.32 & 4.58 & 4.79 & 4.29 & 3.36 & 3.43 & 3.26 \\
\hline
\end{tabular}

Note $-A=$ all subjects $(N=112), W=$ women $(N=66)$, and $M=$ men $(N=46)$. Hits and false alarms are given as percentages. 
Table 2

Pearson Product-Moment Correlations Among Measures of Face Recognition Performance (Hits, False Alarms, d', and $\beta$ ) Over 3 Days of the Study

\begin{tabular}{|c|c|c|c|c|c|c|c|c|c|}
\hline & \multicolumn{3}{|c|}{ All Subjects $(\mathrm{N}=112)$} & \multicolumn{3}{|c|}{ Women $(N=66)$} & \multicolumn{3}{|c|}{$\operatorname{Men}(N=66)$} \\
\hline & $\begin{array}{l}\text { Days } 1 \\
\text { and } 2\end{array}$ & $\begin{array}{r}\text { Days } 2 \\
\text { and } 3\end{array}$ & $\begin{array}{c}\text { Days } 1 \\
\text { and } 3\end{array}$ & $\begin{array}{c}\text { Days } 1 \\
\text { and } 2\end{array}$ & $\begin{array}{c}\text { Days } 2 \\
\text { and } 3\end{array}$ & $\begin{array}{l}\text { Days } 1 \\
\text { and } 3\end{array}$ & $\begin{array}{c}\text { Days } 1 \\
\text { and } 2\end{array}$ & $\begin{array}{l}\text { Days } 2 \\
\text { and } 3\end{array}$ & $\begin{array}{c}\text { Days } 1 \\
\text { and } 3\end{array}$ \\
\hline Hits & .42 & .40 & .36 & .39 & .32 & .26 & .43 & .49 & .46 \\
\hline False Alarms & .47 & .61 & .38 & .37 & .51 & .32 & .58 & .67 & .44 \\
\hline $\mathrm{d}^{\prime}$ & .37 & .49 & .25 & .37 & .41 & .21 & .24 & .60 & .24 \\
\hline$\beta$ & .34 & .39 & .23 & .13 & .37 & .14 & .63 & .42 & .35 \\
\hline
\end{tabular}

performance. Men show a little more consistency than women, but their slightly higher $\mathrm{r}$ values also reflect their wider range of scores.

A further inspection of the raw data, however, provides an indication that more intraindividual consistency in recognition performance is present in some persons than the correlational analysis above makes obvious. Using the means of the $\mathrm{d}^{\prime}$ measures on each day of face recognition, subjects were classified into three groups: those whose performance fell above the mean on all 3 days, that is, consistently good recognizers $(\mathrm{N}=30)$; those whose performance fell below the mean $\mathrm{d}^{\prime}$ on all 3 days, consistently poor recognizers $(\mathrm{N}=28)$; and the remaining subjects, whose performance was inconsistent $(\mathrm{N}=54)$. Looking at the data this way, more than $50 \%$ of subjects tested showed general consistency in their performance, supporting the feasibility of trying to find characteristics that will identify consistent subjects in further research.

In addition, in Table 2 false alarm rates show as good, or better, consistency than hit rates. This observation is especially interesting in view of findings from other visual recognition tasks performed by the same subjects. On three other recognition tasks for which false alarm rates could be scored (snow crystals, scenes, and dot patterns), consistency among the false alarm rates ranges from .29 to .49; those rates when intercorrelated with the false alarm rates for faces on three occasions produce nine values of $\mathrm{r}$ ranging from .26 to .50 . (Similar correlations for hits on faces and other visual task hits range from .06 to .28.) In other words, subjects show moderate consistency in the tendency to make commission errors, over test occasions, and also over different types of material. While the size of the $r$ values are again not large enough to suggest that we could, at the moment, predict individual tendencies toward errors of commission, the observations about false alarm rates could provide a promising direction for future research.

This study approached the question of reliability of face recognition performance from the standpoint of intercorrelations of performance scores on repeated trials, and it also asked whether some persons show more consistency than others. Both kinds of data have implications for interpreting the usefulness and credibility of eyewitness identification testimony. The moderate correlations obtained and the observation that more than $50 \%$ of subjects show consistency in $\mathrm{d}^{\prime}$ accuracy across the three face tasks suggest that while prediction for individuals of eyewitness performance is not currently practical, further research concerning group differences between good and poor recognizers, either in personal characteristics or in recognition behaviors such as false alarm rates, could be of value.

\section{REFERENCES}

Buckноuт, R. Eyewitness testimony. Scientific American, 1974, 231, 23-31.

Chance, J. E., Goldstein, A. G., \& McBride, L. Differential experience and recognition memory for faces. Journal of Social Psychology, 1975, 97, 243-253.

Clifford, B. R., \& Bull, R. The psychology of person identification. London: Routledge \& Kegan Paul, 1978.

Ellis, H. D. Recognizing faces. British Journal of Psychology, $1975,66,409-426$.

Goldste in, A. G. The fallibility of the eyewitness: Psychological evidence. In B. D. Sales (Ed.), Psychology and the legal process. Englewood Cliffs, N.J: Prentice-Hall, 1976.

Neisser, U. Cognitive psychology. New York: AppletonCentury-Crofts, 1967.

(Received for publication May 13, 1979.) 